TERATOLOGY 57:51-55 (1998)

\title{
Adult and Two Children With Fetal Methotrexate Syndrome
}

\author{
E.V. BAWLE, ${ }^{1,2 *}$ J .V. CONARD, ${ }^{1}$ AND L. WEISS ${ }^{2}$ \\ ${ }^{1}$ Children's Hospital of Michigan, WayneStateUniversity, Detroit, Michigan 48201 \\ 2Henry Ford Hospital, Detroit, Michigan 48201
}

\begin{abstract}
The folic acid antagonists, methotrexate and aminopterin, are known to be teratogenic in humans. The critical period for their teratogenecity is suspected to be between 6 to 8 weeks post-conception. Fetal exposure from 10 to 32 weeks weeks post-conception to methotrexate alone or in combination with other anti-cancer drugs has not resulted in obvious teratogenic effects. Methotrexate is often used to treat cancers but is occasionally used as an abortifacient. The long-term outcome of the fetal aminopterin syndrome has been published in only four adults. We report on a 28-year-old man with fetal methotrexate syndrome and two children with mild manifestations of the syndrome. One child was inadvertently exposed to methotrexate from $71 / 2$ through 30 weeks postconception because his mother was receiving it for treatment of breast cancer. The other was exposed from 11 weeks and 5 days through 25 weeks in an attempt to induce abortion. The 28-year-old man has craniofacial and digital anomalies, growth retardation but normal intelligence as noted in the previously reported cases. These cases remind us of the teratogenicity of methotrexate and should serve as a warning that if methotrexate is used as an abortifaciant and an abortion does not ensue, there is a teratogenic risk. Teratology 57:51-55, 1998. @ 1998 Wiley-Liss, Inc.
\end{abstract}

Aminopterin and its methyl derivative, methotrexate, are folic acid antagonists used for the treatment of various cancers, rheumatoid arthritis, psoriasis, and occasionally as abortifaciants for the management of ectopic or unwanted pregnancies. Prenatal exposure to these drugs during critical periods of embryogenesis is known to cause a multiple malformation syndrome in humans. The critical gestation period has been suggested to be from 6 through 8 weeks post-conception by Feldkamp and Carey ('93) and by Donnenfeld et al. ('94). Thethreshold dosefor teratogenicity of methotrexate is thought to be $10 \mathrm{mg}$ per week. The long-term outcome in fetal aminopterin syndrome has been published in four adults. We report on a 28-year-old man with fetal methotrexate syndrome and two children with a partial form of the syndrome.

\section{CASE 1}

We examined $\mathrm{CH}$ at the age of 26 years for multiple anomalies. His parents are African American with no birth defects. His mother had five normal children after him. She attempted to terminate this pregnancy by taking an unknown quantity of methotrexate either 6 weeks post-conception or 6 weeks after the last menstrual period. She gave him up for adoption soon after birth. Some of the birth defects of his hands and feet had been surgically corrected, but since his entire medical record was available, a complete assessment was possible. He has hypertelorism, (interpupillary distance of $6.5 \mathrm{~cm},+2.5$ S.D.), ptosis of the eyelids, short palpebral fissures (length $2.5 \mathrm{~cm}$ ), sparse eyebrows, prominent nose, low-set ears, and a widow's peak at the frontal hairline (Fig. 1). His height was 155 cm (-3 S.D.), weight $39.7 \mathrm{~kg}$ (-2.5 S.D.) and head circumference was $51 \mathrm{cms}(-3.5$ S.D.). He has additional flexion creases on the fingers (Fig. 2A). The " $\mathrm{t}$ " triradius is distally placed. A surgical repair of his flexion contractures of the metacarpo-phalangeal joints of both the thumbs and of syndactyly of all the fingers was done at the age of 6 years. Figure $2 \mathrm{~B}$ is a radiograph of his hands taken at the age of 6 years prior to surgery.

He cannot fully extend his el bows due to subluxation of the radial heads (Fig. 3). His great toes are broad. He had surgical reconstruction of all the toes from a single fused hypoplastic nub of tissue at the for efoot. He has only four metacarpals and severe hypoplasia of phalanges of the toes (see Fig. 4A, B). His genitalia are normal. He devel oped gynecomastia at puberty for which he had surgery. Radiographs also demonstrated defects in the bones of the skull (Fig. 5). His early psychomotor

*Correspondence to: Erawati V. Bawle, M.D., Division of Genetics, Children's Hospital of Michigan, 3901 Beaubien, Detroit, MI 48201.

Received 27 May 1997; Accepted 4 December 1997 


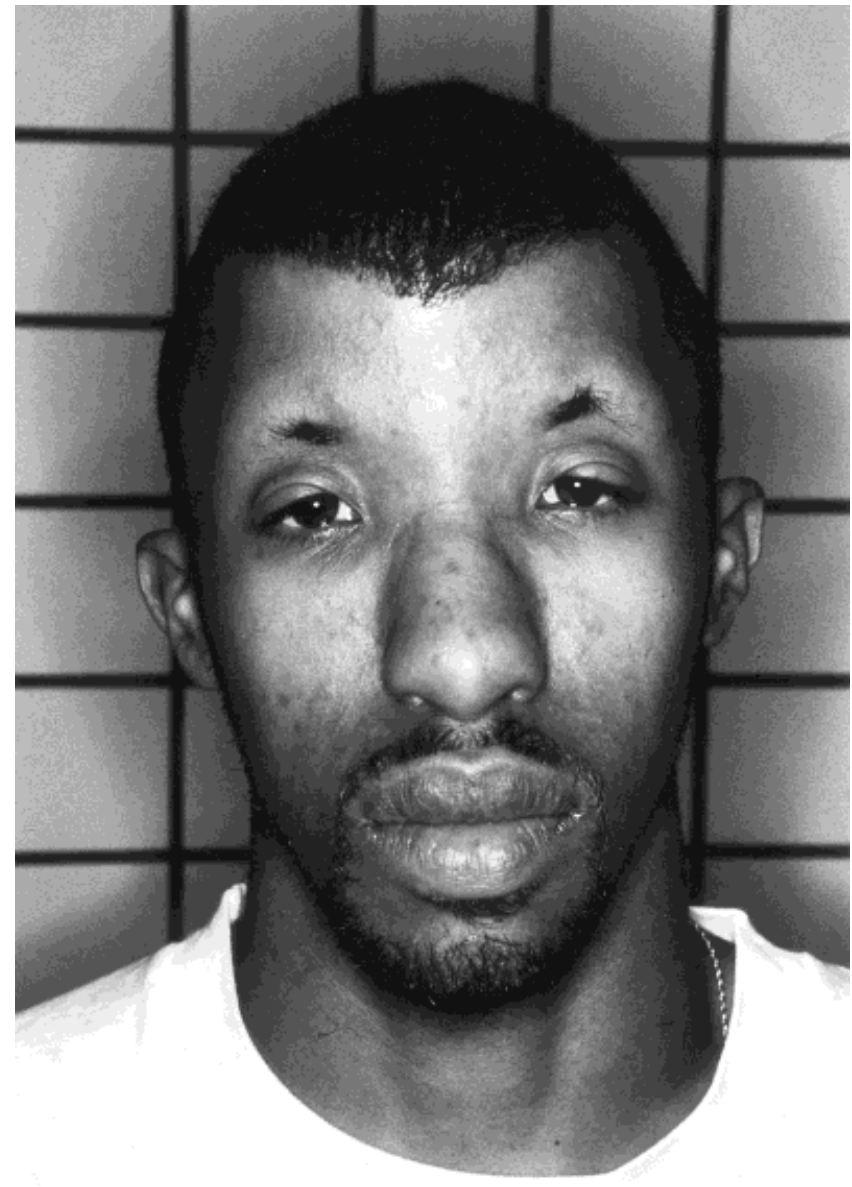

Fig. 1. Case 1 showing hypertel orism, sparse eyebrows, low-set ears, and prominent nose.

development was normal and he passed 11th grade in a regular classroom without any learning difficulties. He is empl oyed as a janitor in the family business. Hehas a driver's license. He seems well adjusted to his condition. His phenotype is compared to the published reports of adults with this syndrome in Table 1.

\section{CASE 2}

Nine-year-old MP was born to a 45-year-ol d gravida 4 para 4 Caucasian woman at 29 weeks gestation weighing $820 \mathrm{~g}$ (small for gestation). His mother's pregnancy was undetected until she went into labor. About 4 weeks after her estimated date of conception (i.e., six weeks after her last menstrual period) she had a lumpectomy for breast cancer. She began chemotherapy with methotrexate at $71 \frac{1}{2}$ weeks post-conception. $\mathrm{Her}$ chemotherapy schedule was as follows: $80 \mathrm{mg}$ methotrexate weekly at 7.5, 8.5, 11.5, 12.5, 23.5, and 28.5 weeks post-conception. She also received 5fluorouracil 1,200 mg weekly at 7.5, 8.5, 11.5, 12.5, 15.5, $16.5,19.5,20.5,23.5$, and 28.5 weeks post-conception. She received radiation therapy (to the breast and chest
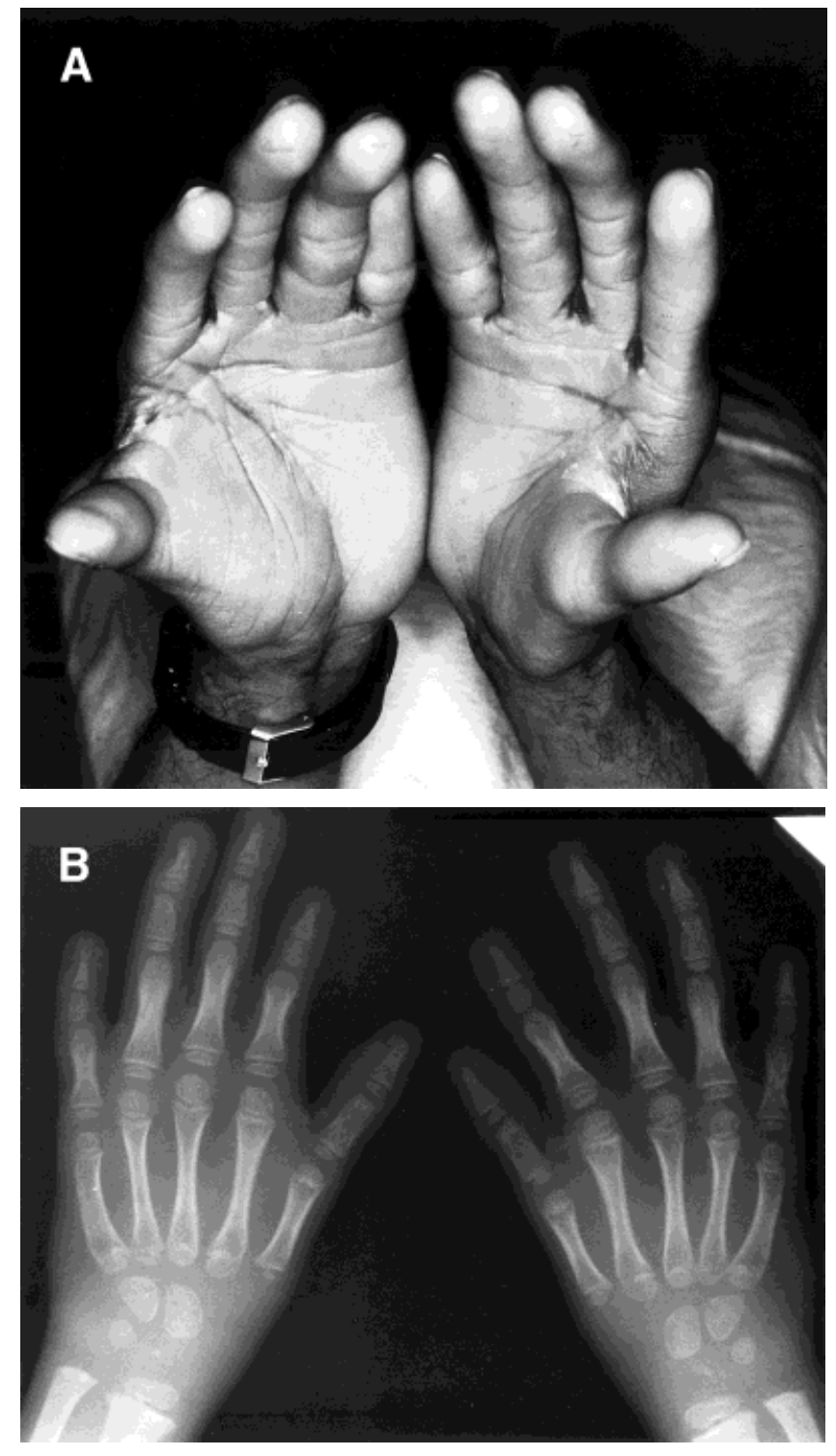

Fig. 2. A: Hands of Case 1 showing excess flexion creases. B: Radiographs of hands of Case 1 at age 6 years prior to surgery, showing syndactyly of fingers and hypoplasia of middle phalanges of $2 \mathrm{nd}$ and 5th fingers.

wall area) from 15.5 weeks through 25 weeks postconception. Thetotal fetal radiation dose was estimated to be 14 rads. MP's karyotype was normal.

At $8 \frac{1}{2}$ years his height was $107 \mathrm{~cm}$ (-4 S.D.), weight $16 \mathrm{~kg}$ ( -3 to 4 S.D.), and head circumference $47 \mathrm{cms}$ ( -4 S.D.). He has hypertelorism, a frontal hair whorl, an upsweep of the frontal hairline, microcephaly, low-set ears, micrognathia (Fig. 6), and a right palmar simean crease. The extremities are normal. On Stanford Binet I ntelligencetest IV-revised, he earned a composite IQ of 70. This is in the "mentally deficient"tolow "borderline" limits of intelligence compared with other students his age. $\mathrm{H}$ is speech and language skills are in the mildly 


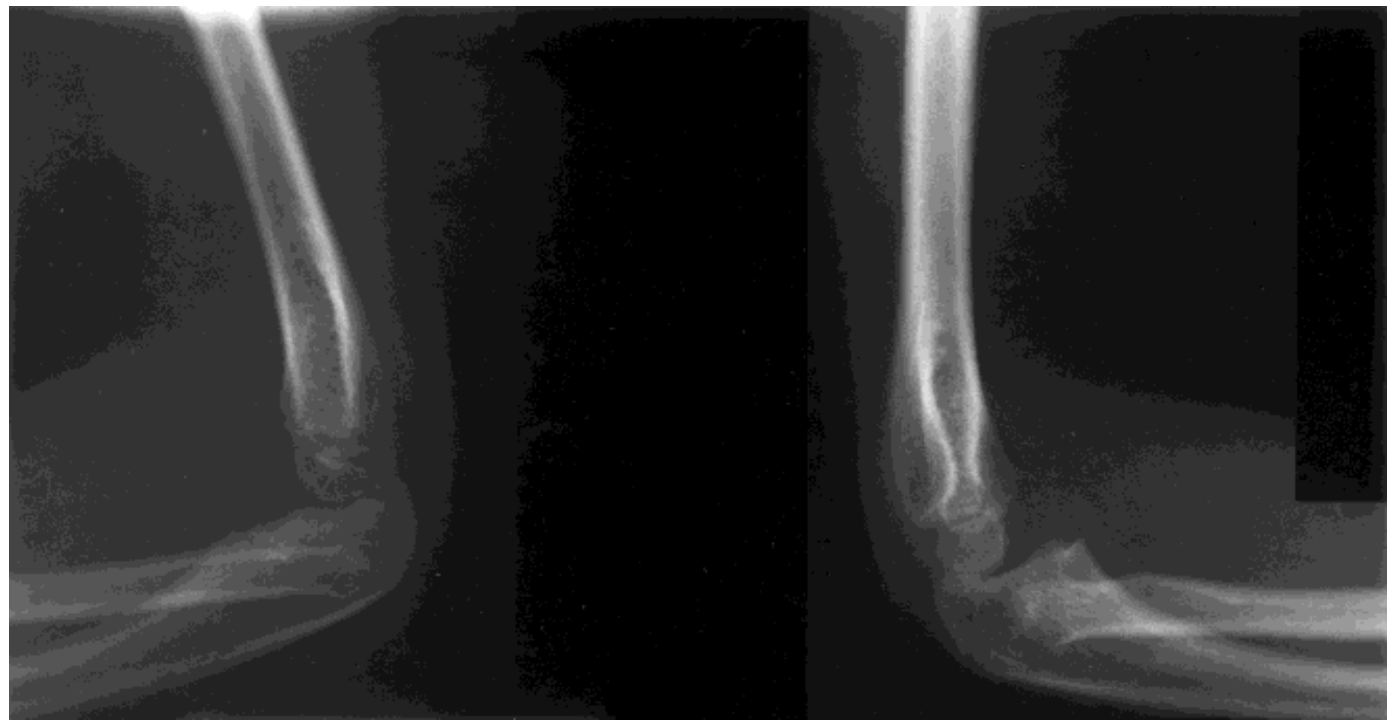

Fig. 3. Case 1 showing subluxation of radial heads.
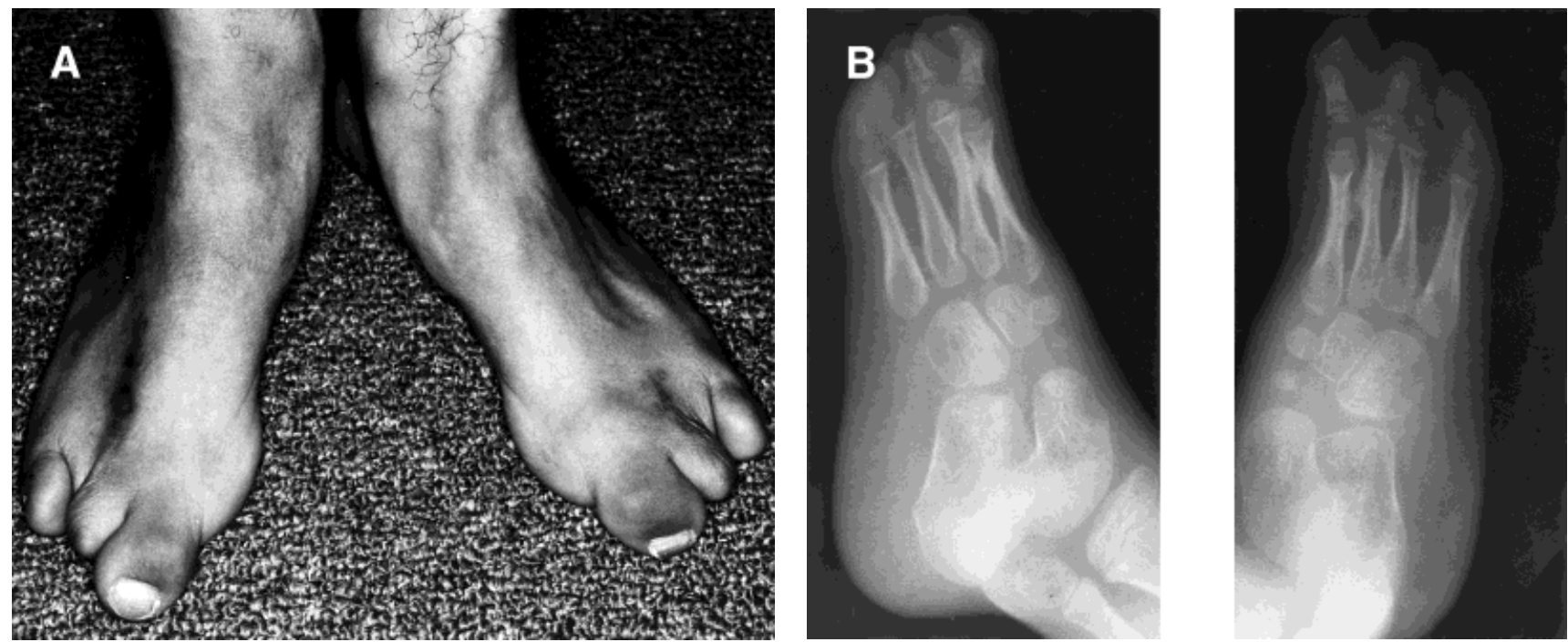

Fig. 4. A,B: F eet of Case 1 with only 4 metacarpals and hypoplasia of toes.

mentally deficient range. He stutters and has verbal expressive difficulties. Hedoes not show any behavioral abnormalities and gets al ong with classmates.

\section{CASE 3}

Three-and-a-half-year-old DC was born at 29 weeks gestation weighing $1,160 \mathrm{~g}$ (approximately 50 th percentile) to a then 33-year-old gravida 1 para 1 woman of African-American descent. At 9 weeks post-conception (i.e., 11 weeks after her last menstrual period) she underwent dilatation, suction, and curettage in an attempted el ective abortion. Two weeks later, being still pregnant, she was offered an abortion via a hysterotomy. The hysterotomy was recommended because of the risk of hemorrhage from large uterine myomas. Instead, she chose to have a medical abortion with methotrexate. Her methotrexate schedule was $100 \mathrm{mg}$ bi-weekly from 11 weeks and 5 days to 17 weeks post-conception and $200 \mathrm{mg}$ bi-weekly from 17 to 23 weeks post-conception. At 34 months of age his weight was $10 \mathrm{~kg}$ (-3.5 S.D.), length $87 \mathrm{~cm}$ (-3 S.D.), and his head circumference was $51.5 \mathrm{~cm}$ (75th percentile). He has a bulging forehead, bitemporal narrowing, upward slanting pal pebral fissures, sparse hair on the temporal areas, low-set ears, broad nasal tip, and a high arched palate. His psychomotor development is normal. The family did not consent for publication of DC's photographs. Chronic diarrhea since the age of 9 months was 


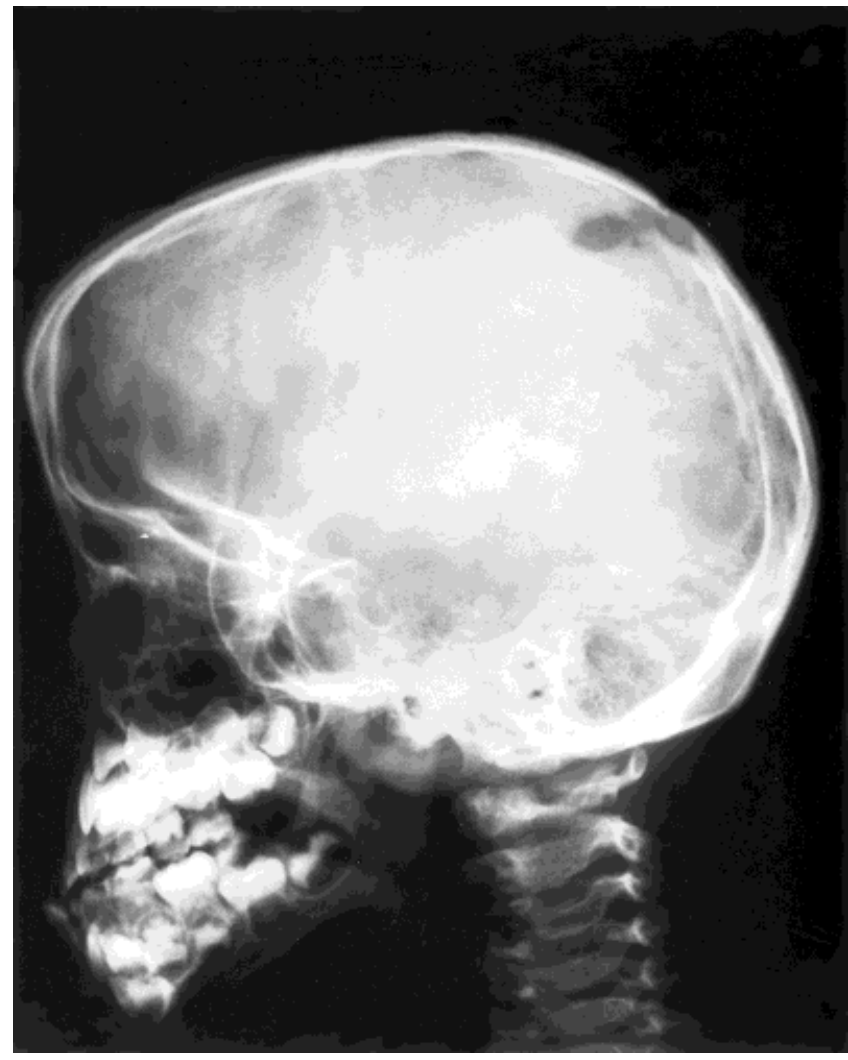

Fig. 5. Case 1 with skull defects.

considered the cause of his poor weight gain. Extensive investigations for the diarrhea have not led to a specific diagnosis. An intestinal biopsy initially showed villous atrophy.

\section{DISCUSSION}

Thiersch ('52,'56), Meltzer ('56), and Warkany et al. ('59) reported fetal malformations associated with maternal ingestion of aminopterin. Subsequent reports include those by Milunsky et al. ('68), Shaw and Steinbach ('68), Powell and Eckert ('71), Howard and Rudd ('77), Reich et al. ('78), and Shaw and Rees ('80). Many children with aminopterin embryopathy died in infancy. There have been no reported cases since 1980. The risk for malformation is not $100 \%$ as shown by the reports of F reedman et al. ('62) and Pizzuto et al. ('80). Feldkamp and Carey ('93) reviewed published cases of fetal aminopterin syndrome and suggested that the critical period for the development of malformations is 6 through 8 weeks post-conception and the minimum dose to be $10 \mathrm{mg}$ per week.

Our Case 2 was initially exposed at $71 / 2$ weeks at a much larger dose, but did not develop the digital anomalies. Similarly, the case reported by Shaw and Steinbach ('68), who was exposed from 8-9 weeks, and Howard and Rudd's ('77) patient exposed at 8 weeks showed no digital anomalies. Our Case 2 was also
TABLE 1. Comparison of clinical data of 5 adult patients with fetal aminopterin/methotrexate syndrome

\begin{tabular}{|c|c|c|c|c|c|}
\hline & \multirow{2}{*}{$\begin{array}{l}\text { Our } \\
\text { case } 1\end{array}$} & \multicolumn{3}{|c|}{ Reich et al. ('78) } & \multirow{2}{*}{$\begin{array}{l}\text { Shaw and } \\
\text { Steinbach } \\
\text { ('68) }\end{array}$} \\
\hline & & Case 1 & Case 2 & Case 3 & \\
\hline \multicolumn{6}{|l|}{ Aminopterin } \\
\hline Methotrexate & & & & & \\
\hline exposure & + & $?$ & - & $?$ & - \\
\hline $\begin{array}{l}\text { Time of exposure } \\
\text { in weeks }\end{array}$ & $6-8$ & 8-12 & $6-8$ & $?$ & $8-9$ \\
\hline $\begin{array}{l}\text { Bitemporal flat- } \\
\text { tening, brachy- } \\
\text { cephaly }\end{array}$ & + & + & + & + & - \\
\hline Characteristic & & & & & \\
\hline $\begin{array}{l}\text { frontal hairline } \\
\text { Hypoplastic }\end{array}$ & + & + & + & + & + \\
\hline $\begin{array}{l}\text { supraorbital } \\
\text { ridges }\end{array}$ & - & + & + & + & + \\
\hline $\begin{array}{l}\text { Sparse and faint } \\
\text { eyebrows, lat- } \\
\text { eral half }\end{array}$ & + & + & + & + & + \\
\hline Hypertelorism & + & + & + & + & + \\
\hline $\begin{array}{l}\text { Prominent eye- } \\
\text { balls }\end{array}$ & - & - & + & + & + \\
\hline $\begin{array}{l}\text { Small palpebral } \\
\text { fissures }\end{array}$ & + & + & + & + & + \\
\hline $\begin{array}{l}\text { Prominent nose } \\
\text { High arched }\end{array}$ & + & + & + & + & + \\
\hline palate & + & + & + & + & + \\
\hline Micrognathia & - & + & + & + & + \\
\hline $\begin{array}{l}\text { Low-set ears or } \\
\text { malformed ears }\end{array}$ & + & + & + & + & + \\
\hline Microcephaly & + & - & - & - & + \\
\hline $\begin{array}{l}\text { Distal shortening } \\
\text { of limbs }\end{array}$ & - & + & + & + & + \\
\hline $\begin{array}{l}\text { Limitation of } \\
\text { rotation and } \\
\text { extension of } \\
\text { elbows }\end{array}$ & + & + & + & + & + \\
\hline $\begin{array}{l}\text { Subluxation of } \\
\text { radial heads } \\
\text { Defects in skull }\end{array}$ & + & + & + & + & + \\
\hline bones & + & + & - & + & + \\
\hline $\begin{array}{l}\text { Brachydactyly/ } \\
\text { syndactyly/hy- }\end{array}$ & & & & & \\
\hline $\begin{array}{c}\text { poplasia digits } \\
\text { Abnormal derma- }\end{array}$ & + & + & + & + & - \\
\hline toglyphics & + & + & + & + & - \\
\hline $\begin{array}{l}\text { Short stature } \\
\text { Normal intelli- }\end{array}$ & + & + & + & + & + \\
\hline gence & + & + & + & + & + \\
\hline
\end{tabular}

exposed to 5-fluorouracil from 7.5 weeks post-conception. Experience with 5-fluorouracil during pregnancy is limited but, following systemic therapy in the first trimester, Stephens et al. ('80) reported multiple birth defects in an aborted fetus: radial aplasia, absent fingers, aplasia of the esophagus and duodenum. Our patient does not show these anomalies.

Case 3 in this report was exposed at 11 weeks and 5 days and onward, and showed a different and milder phenotype. This case suggests that the teratogenecity of methotrexate may extend through 11 weeks post- 


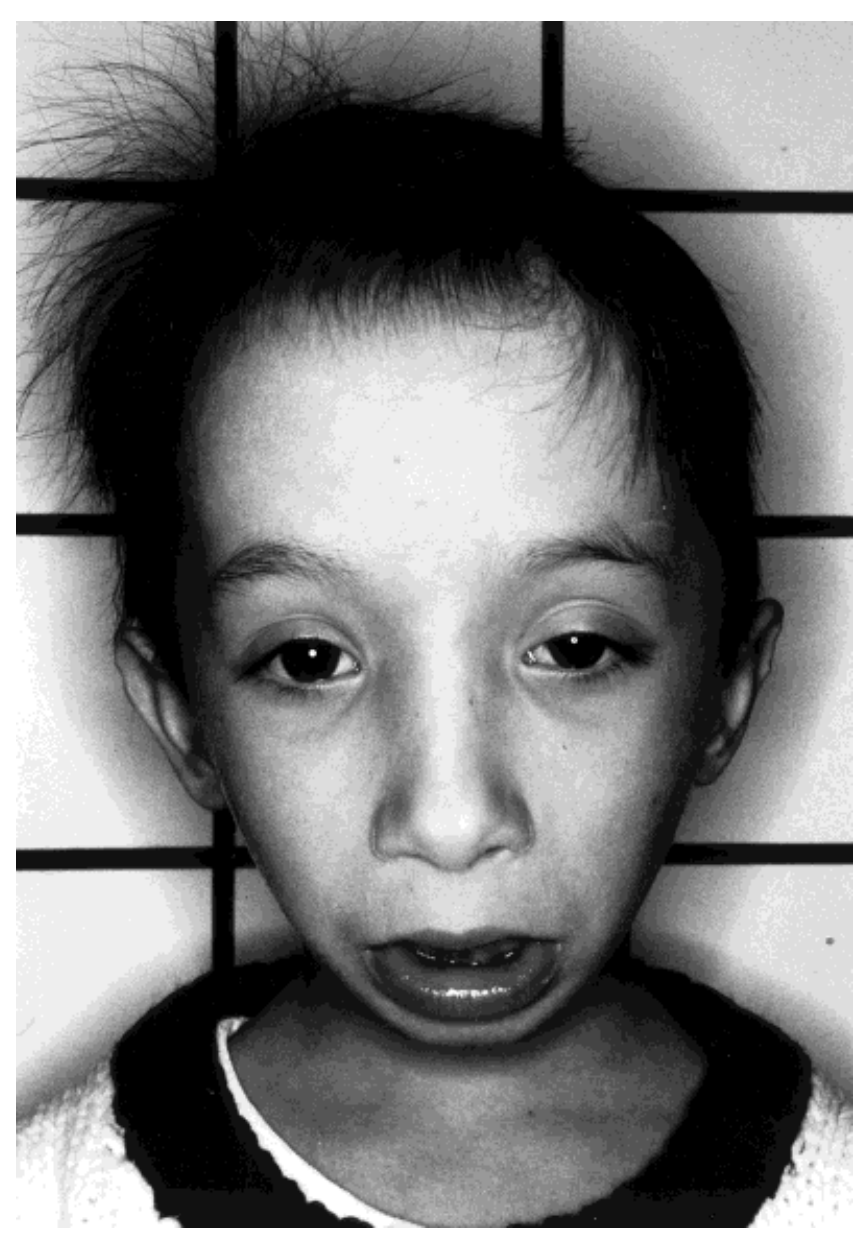

Fig. 6. Case 2 showing hypertelorism, upsweep of frontal hair line, and micrognathia.

conception but the syndromethen is milder. Methotrexate is useful in the treatment of many types of cancers, rheumatoid arthritis, and psoriasis. It has been shown to be safe and effective in medical treatment of ectopic pregnancy as reviewed by Slaughter and Grimes ('95). Methotrexate followed by misoprostol has been pro- posed as a means of terminating very early pregnancies. Failed treatment carries the risk of the fetal methotrexate syndrome.

\section{LITERATURE CITED}

Donnenfeld, A.E., A. Pastuszak, J S. Noah, B. Schick, N.C. Rose, and G. Koven (1994) Methotrexate exposure prior to and during pregnancy (letter to the editor). Teratology, 49:79-81.

Feldkamp, M., and J.C. Carey (1993) Clinical teratology counseling and consultation case report: Low dose methotrexate exposure in the early weeks of pregnancy. Teratology, 47:533-539.

Freedman, H.L., A. Maganini, and M. Glass (1962) Pregnancies following chemically treated choriocarcinoma. Am. J . Obstet. Gynecol., 83:1637-1641.

Howard, N.J ., and N.L. Rudd (1977) The natural history of aminopterin-induced embryopathy. Birth Defects, 13:85-93.

Meltzer, H.J . (1956) Congenital anomalies due to attempted abortion with 4-aminopteroglutamic acid. J .A.M.A., 161:1253.

Milunsky, A., J.W. Graef, and M.F. Gaynor, J r. (1968) Methotrexateinduced congenital malformations. J. Pediatr., 72:790-795.

Pizzuto, J ., A. Aviles, L. Noriega, J . Niz, M. Morales, and F. Romero (1980) Treatment of acuteleukemia during pregnancy: Presentation of nine cases. Cancer Treat. Rep., 64:679-683.

Powell, H.R., and H. Ekert (1971) Methotrexate-induced congenital malformations. Med. J . Aust., 2:1076-1077.

Reich, E.W., R.P. Cox, M.H. Becker, N.B. Genieser, J .G. McCarthy, and J .M. Converse (1978) Recognition in adult parents of malformations induced by folic-acid antagonists. Birth Defects, 14:139-160.

Shaw, E.B., and E.L. Rees (1980) Fetal damage due to aminopterin ingestion: Follow-up at 171/2 years of age. Am. J. Dis. Child. 134:1172-1173.

Shaw, E.B., and H.L. Steinbach (1968) Aminopterin-induced fetal malformation: Survival of infant after attempted abortion. Am. J . Dis. Child., 115:477-482.

Slaughter, J L. and D.A. Grimes (1995) Methotrexate therapy. Nonsurgical management of ectopic pregnancy. West. J . Med. 162:225228.

Stephens, J .D., M.S. Golbus, T.R. Miller, R.R. Wilber, and C.J . E pstein (1980) Multiple congenital anomalies in a fetus exposed to 5fluorouracil during the first trimester. Am. J. Obstet. Gynecol. 137:747-749.

Thiersch, J.B. (1952) Therapeutic abortions with a folic acid antagonist, 4-aminopteroylglutamic acid (4-amino P.G.A.) administered by the oral route. Am. J . Obstet. Gynecol., 63:1298-1304.

Thiersch, J .B. (1956) The control of reproduction in rats with the aid of antimetabolites, and early experiences with antimetabolites as abortifacient agents in man. Acta Endocrinol., 28(Suppl):37-45.

Warkany, J ., P.H. Beaudry, and S. Hornstein (1959) Attempted abortion with aminopterin (4-aminopteroylglutamic acid): Malformations of the child. Am. J . Dis. Child., 97:274-281. 